\title{
The prevalence of proteinuria in patients presenting with fluid retention due to heart failure
}

\author{
${ }^{1} \mathrm{~K}$ Peeroo, ${ }^{2} \mathrm{~A}$ Clark \\ ${ }^{1}$ Specialty Registrar, Hull Royal Infirmary; ${ }^{2}$ Reader and Honorary Consultant Cardiologist, Castle Hill Hospital, Cottingham, UK
}

\begin{abstract}
The prevalence of proteinuria in patients presenting acutely with oedema due to heart failure has not been studied extensively. Recent evidence from the Candesartan in Heart failure Assessment of Reduction in Mortality and morbidity (CHARM) trial suggests that there is a high prevalence of albuminuria in chronic heart failure patients. We set out to investigate the prevalence of proteinuria in patients presenting with fluid retention secondary to heart failure. A random collection of urine albumin-creatinine ratios (ACRs) in successive patients was used to quantify proteinuria. Out of a sample of 19 patients, seven had no detectable albuminuria, eight had microalbuminuria and four had macroalbuminuria. We did not find any relation between urine ACR and age, serum urea or serum creatinine. Moreover, we did not find a higher prevalence of albuminuria with increasing age or the presence of diabetes mellitus. In conclusion, the clinical significance of this common finding in patients presenting with fluid retention is not clear, and further research is warranted to clarify its prognostic value.
\end{abstract}

KEYWORDS Heart failure, oedema, macroalbuminuria, microalbuminuria, proteinuria

DECLARATION OF INTERESTS No conflict of interests declared.
Correspondence to $K$ Peeroo, Department of Medicine for the Elderly, Hull Royal Infirmary, Anlaby Road, Hull HU3 2JZ, UK

tel. +44 (0) I 482875875 e-mail khalill.peeroo@gmail.com

\section{INTRODUCTION}

The prevalence of proteinuria in patients with oedematous heart failure has not been studied in depth, although reduced renal function is both very common and a very potent independent predictor of an adverse outcome in patients with cardiovascular disease. ${ }^{1,2}$ Jackson et al. ${ }^{3}$ found a prevalence of albuminuria of $41 \%$ in patients with chronic heart failure entered into the Candesartan in Heart failure Assessment of Reduction in Mortality and morbidity (CHARM) trial of patients with chronic stable heart failure. Proteinuria was associated with increasing age and a diagnosis of diabetes. Urine albumin-creatinine ratio (ACR) was a powerful and independent predictor of prognosis.

Microalbuminuria reflects generalised vascular endothelial dysfunction, its prevalence ranging from $6-10 \%$ in populations of apparently healthy subjects in the US and Europe. ${ }^{2,4}$ We wanted to find out the prevalence of proteinuria in patients presenting with an episode of fluid retention due to heart failure.

\section{METHODS}

We report on consecutive patients presenting at Hull and East Yorkshire Hospitals NHS Trust with a diagnosis of fluid retention secondary to heart failure. Urine dipstick and spot $A \mathrm{CR}^{5,6}$ were collected as soon as possible after admission, all within 24 hours from initial presentation. Microalbuminuria was defined as urine ACR of $>2.5 \mathrm{mg} / \mathrm{mmol}$ and macroalbuminuria as $>30$ $\mathrm{mg} / \mathrm{mmol} .{ }^{5,6}$ Other data were collected for patient demographics, initial treatment administered for heart failure, medications at presentation and discharge, baseline biochemical profile, full blood count, serum C-reactive protein (CRP), left ventricular (LV) function on 2D-echocardiography and daily weight measurements throughout the admission. Estimated glomerular filtration rate (eGFR) was derived using the abbreviated Modification of Diet in Renal Disease (MDRD), as recommended by the National Institute for Health and Clinical Excellence ${ }^{6}$ and the Renal Association (UK). ${ }^{5}$ Beta blockers, angiotensin-converting enzyme (ACE) inhibitors, angiotensin-2 receptor antagonists, loop diuretics and aldosterone antagonists and digoxin were considered to be heart failure medications. Data were analysed using Microsoft ${ }^{\circledR}$ Excel $^{\text {TM }}$.

\section{RESULTS}

A total of 29 patients were enrolled, but only 19 were eligible for analysis because ACR was not performed in time in the other 10 . Of the 19 patients, 12 (63.2\%) were male. A clinical diagnosis of heart failure was made on the basis of fluid retention: patients all had raised jugular venous pressure and pitting oedema up to the knees at least. Age ranged from 53 to 93 years, with a mean of 72.9 and median of 73 . The length of in-hospital stay varied from three to 49 days, with a median duration of 12 days, and on average patients' weight decreased by $5.1 \mathrm{~kg}$ during admission.

By far the most common initial treatment instituted was intravenous furosemide - 15 (78.9\%) out of 19 . Two patients received furosemide orally, while the remaining 
TABLE I Characteristics of heart failure patients with and without macroalbuminuria at acute presentation

\begin{tabular}{|c|c|c|c|}
\hline Variable & $\begin{array}{l}\text { Macro- } \\
\text { albuminuria } \\
(n=4)\end{array}$ & $\begin{array}{l}\text { No macro- } \\
\text { albuminuria } \\
(n=15)\end{array}$ & $\mathbf{p}$ \\
\hline Age & $70.5(10.6)$ & $82.3(9.7)$ & 0.09 \\
\hline Male sex & $50 \%$ & $67 \%$ & \\
\hline $\begin{array}{l}\%>\text { mild LV systolic } \\
\text { impairment }\end{array}$ & $50 \%$ & $36.8 \%$ & \\
\hline Haemoglobin (g/dl) & II.8 (2.9) & $11.9(3.3)$ & 1.0 \\
\hline Sodium (mmol/l) & $136.2(3.7)$ & $137.3(3.6)$ & 0.6 \\
\hline Potassium (mmol/l) & $4.1(0.7)$ & $4.5(0.7)$ & 0.4 \\
\hline Urea $(\mathrm{mmol} / \mathrm{l})$ & $10.1(10.2)$ & $7.1(2.4)$ & 0.3 \\
\hline Creatinine $(\mu \mathrm{mol} / \mathrm{l})$ & $114.6(70.2)$ & $111.5(16.2)$ & 0.9 \\
\hline
\end{tabular}

All values expressed as mean ( \pm standard deviation) where appropriate.

two had bumetanide. The median number of heart failure medications on admission was two, increasing to four at discharge. Out of the 19 patients, 10 (52.6\%) had been on drugs that affect the degree of proteinuria. Of these, four (40\%) had normal albumin excretion, three (30\%) had microalbuminuria and three (30\%) had macroalbuminuria.

On echocardiography, LV systolic function was good in five cases (26.3\%), mildly impaired and moderately impaired in five cases each, and severely impaired in four cases. Of the five with good LV function, four had right heart failure and pulmonary hypertension and one had a prosthetic mitral valve with severe tricuspid regurgitation. Among the five with mild LV impairment, one had restrictive cardiomyopathy and atrial fibrillation, one had dilated cardiomyopathy, one had mild LV hypertrophy and ischaemic heart disease, and one had ischaemic heart disease and stage 3 chronic kidney disease (CKD).

A total of $42.1 \%$ had microalbuminuria and $21.1 \%$ had macroalbuminuria, with one patient in the latter category being in the nephrotic range (ACR $>300 \mathrm{mg} / \mathrm{mmol}$ ). Seven patients had stage I or 2 CKD and eight had stage 3 CKD. Two had normal renal function and two had stage 5 CKD.

The prevalence of macroalbuminuria was similar in the subgroups with preserved and reduced LV function (50\% in each of good/mild vs moderate/severe LV impairment). However, we did not find a higher prevalence of proteinuria with increasing age or incidence of diabetes mellitus.

There were four patients with diabetes (21.1\%). All four were on medication known to reduce proteinuria. Out

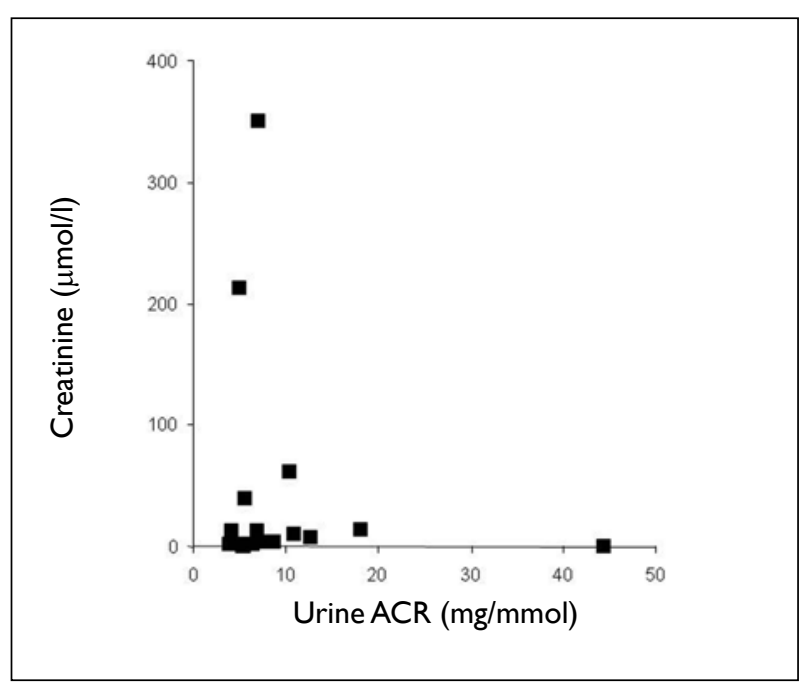

FIGURE I Scatter plot showing the distribution of serum creatinine against urine albumin-creatinine ratio (ACR).

of these, three had normoalbuminuria - two were on an ACE inhibitor (ramipril and lisinopril) and one was on an angiotensin-receptor blocker (valsartan). The fourth patient was in the microalbuminuric range and had been on ramipril.

A comparison between those with and without macroalbuminuria is shown in Table I. There was no relation between urine $A C R$ and age $(p=0.2)$, urea $(p=0.6)$ or creatinine $(p=0.9)$. A scatter plot showing the relation of $A C R$ with serum creatinine is shown in Figure I.

\section{DISCUSSION}

We found that approximately two-thirds of patients presenting acutely with fluid retention due to heart failure had microalbuminuria or macroalbuminuria as defined by an ACR $>2.5 \mathrm{mg} / \mathrm{mmol}$. While recent evidence suggests that an elevated urine $A C R$ is associated with an increased risk of composite outcomes and death in patients with chronic heart failure, ${ }^{3}$ the prevalence of proteinuria in patients presenting acutely has not previously been studied. We found no relation between age, renal function, drug therapy or the presence of diabetes and the prevalence of proteinuria.

We were prompted to see how common proteinuria was in patients presenting with fluid retention by the observation that routine urine dipstick tests were sometimes positive. The clinical significance of this finding is unclear, and further work is necessary to examine the clinical correlates and effects on outcome of this apparently common finding. 


\section{REFERENCES}

I Hillege HL, Nitsch D, Pfeffer MA et al. Renal function as a predictor of outcome in a broad spectrum of patients with heart failure. Circulation 2006; I I3:67I-8. doi: I0. I I6I/CIRCULATIONAHA. I05.580506

2 Karalliedde J, Viberti G. Microalbuminuria and cardiovascular risk. Am J Hypertens 2004; 17:986-93. doi:I0.1016/j.amjhyper.2004.08.010

3 Jackson CE, Solomon SD, Gerstein $\mathrm{HC}$ et al. Albuminuria in chronic heart failure: prevalence and prognostic importance. Lancet 2009; 374:543-50. doi:10.1016/S0140-6736(09)6I378-7
4 Diercks GF, Stroes ES, van Boven AJ et al. Urinary albumin excretion is related to cardiovascular risk indicators, not to flowmediated vasodilation, in apparently healthy subjects. Atherosclerosis 2002; I63:12I-6. doi:I0.1016/S002I-9150(0I)00748-I

5 Taal MW, Tomson C. Clinical practice guidelines. Module I: chronic kidney disease. Petersfield: UK Renal Association; 2007. Available from: http://www.renal.org/Clinical/GuidelinesSection/CKD.aspx

6 National Institute for Health and Clinical Excellence. Chronic kidney disease. London: NICE; 2008. Available from: http://guidance nice.org.uk/CG73/Guidance/pdf/English

\section{$20 I$ I SYMPOSIA}

- Hot topic: Patient safety

19 January

Northern Ireland Symposium: Update in medicine 27 January

Dundee Symposium: Moving points in medicine 9 February

Respiratory medicine

4 March

- Aberdeen symposium: Medical interfaces series:

Gastroenterology and renal medicine

9 March

- Public health policy development and implementation:

Competing pressure in the formulation of state health policy

10 March

- Palliative care (RCPE/RCGP joint symposium) 28 March

- Care of the elderly (RCPE/RCGP joint symposium) I April

\begin{tabular}{ll}
\hline Haematology & May \\
\hline
\end{tabular}

Maternal medicine (RCPE in association with RCOG) 2 June

Infectious diseases 16 June

Stockton symposium: Recent advances in medicine 30 June

- Dermatology

21 September

Paediatrics (RCPE/RCPCH joint symposium)

29 September

Gastroenterology 4 October

Diabetes 7 October

Renal Medicine 13 October

Trainees \& Members' Committee symposium 28 October

Neurology (RCPE/RCGP joint symposium) 16 November

Cardiology

25 November

- 5 Ist St Andrew's Day Festival Symposium:

Updates on Acute Medicine

I-2 December

Looking ahead, the College is planning its next Consensus Conference, on Atrial Fibrillation, for I-2 March 2012.
All symposia are held at the Royal College of Physicians of Edinburgh unless otherwise stated. Further symposia may be added at a later date.

Programme details at: http://events.rcpe.ac.uk or contact the Symposium Co-ordinator: Tel: 013। 2257324

Email: e.strawn@rcpe.ac.uk

Webstreamed lectures

If you are unable to attend symposia at the College in Edinburgh, selected lectures from all symposia are available to view and listen to in the Online Education section of the secure area of the College website. There are currently more than 100 lectures covering all the medical specialties and a range of generic topics.

\begin{tabular}{|c|}
\hline Book online at \\
http://events.rcpe.ac.uk \\
\hline
\end{tabular}

